\title{
The Evaluation of Low-carbon Economy Based on Entropy Coefficient-TOPSIS Method: A Survey in Hebei Province
}

\author{
LI Xianshi, ${ }^{1,2}$ \\ ${ }^{1}$ Beijing Institute of Technology, China \\ ${ }^{2}$ Shijiazhuang University of Economics, China \\ lixianshilxs@sina.com
}

Keywords: Hebei province; low-carbon economy; entropy coefficient; TOPSIS; DPSIR.

\begin{abstract}
This paper constructed a low-carbon economy evaluation index system based on DPSIR framework model in Hebei province. The framework consists of five dimensions, namely the driving force, pressure, state, impact and response. It evaluated and analyzed the situation of low-carbon economic development from 2007 to 2013 by using entropy coefficient-TOPSIS method. The results showed that the trend of low-carbon economic development in Hebei province was increasing in the past seven years, which the evaluation value increased from 0.35967 in 2007 to 0.68083 in 2013 . The development path was type $U$ in the past seven years, which showed the development of low-carbon economy wasn't steady in Hebei province. It is normal for the temporary volatility in the development of low-carbon economy, but the general trend is toward positive direction.
\end{abstract}

\section{Introduction}

At present, with the rapid development of Chinese economy, it emerges the incompatible problems of the economy, society, population, resources and environment gradually. The environmental pollution and the resources shortage become the bottleneck of the development, which led to discuss the issues of low-carbon economy model. In the 3rd Plenary Session of the 18th Central Committee of the Communist Party of China[1], the plenum pointed out, We must deepen ecological environment management reform by centering on building a beautiful China. We should accelerate system building to promote ecological progress, improve institutions and mechanisms for developing geographical space, conserving resources and protecting the ecological environment and promoting modernization featuring harmonious development between Human and Nature.

On the current situation of Hebei province, because of the low quality of economic growth and low utilization efficiency of natural resources, the serious environmental constraints, the provincial government proposed to support the development of energy-efficient and low-carbon industries in the Fifth Session of the Eighth Congress of Hebei Province in 2013. Therefore, analysis and evaluation of the development level of low-carbon economy in Hebei province can provide decision-making reference for Hebei province, it will help to raise our ecological awareness and optimize the industrial structure.

Viewed some of the existing literature, the evaluation on the low-carbon economy mainly included the methods, research scope and index system construction [2-8]. Many scholars had studied on the low-carbon economy of different regions by using different methods and different indexes. From the perspective of evaluation approaches, many scholars used the multi index comprehensive evaluation method. The subjective weighting method mainly included AHP, comprehensive evaluation method, and fuzzy evaluation method. Objective weighting method mainly included the entropy method, osculating value method, TOPSIS method, grey correlation method, variation coefficient method, factor analysis, data envelopment analysis.

The main objective of this paper was to evaluate and analyze the low-carbon economy in Hebei province by using the method of entropy method and TOPSIS. The TOPSIS (Technique for Order Preference by Similarity to Ideal Solution) method has the advantages of wide application range, small amount of calculation and intuitive geometric meaning, which was widely used in the study of 
the ecological economy and related evaluation [9]. In order to avoid the influence of subjective factors on the ranking results, we used the entropy method to determine the weight.

\section{The construction of the index system of low-carbon economy}

In this paper, it constructed the evaluation index system of low-carbon economy in Hebei province based on the framework of DPSIR model. The framework consists of five dimensions, namely the driving force, pressure, state, impact and response, which proposed in 1999 by the European Environment Agency (EEA). [10].The DPSIR model was commonly used in analyzing the ecological problems and social development. [11-13]

The system had three layers. The first layer was the target layer, which named the low-carbon economy evaluation value in Hebei Province. The second layer was the five factors index. They were driving force (D), pressure (P), state (S), impact (I) and response (R). The third layer was the index, which was subdivided into 31 specific indicators based on the above five factors. See Table 1.

Table 1.The evaluation index system of low-carbon economy in Hebei Province

\begin{tabular}{|c|c|c|c|}
\hline Factor index & Index & Unit & Type \\
\hline \multirow{7}{*}{ Driving force } & Total Population & 10 thousand & Cost \\
\hline & Natural Growth Rate & $\%$ & Cost \\
\hline & Urbanization Level & $\%$ & Cost \\
\hline & GDP & 100 million Yuan & Benefit \\
\hline & Per Capita GDP & Yuan & Benefit \\
\hline & $\begin{array}{l}\text { Per Capita Annual Disposable Income of Urban } \\
\text { Residents }\end{array}$ & Yuan/ Per Capita & Benefit \\
\hline & Per Capita Annual Net Income of Rural Households & Yuan/ Per Capita & Benefit \\
\hline \multirow{5}{*}{ Pressure } & Car Parc & 10 thousand unit & Cost \\
\hline & Energy Consumption per Unit of GDP & Tons of SCE / million & Cost \\
\hline & Power Consumption of the City & 100 million kwh & Cost \\
\hline & Freight Ton-kilometers & 100 million ton-km & Cost \\
\hline & Passenger kilometers & $\begin{array}{ll}100 & \text { million } \\
\text { passenger-km }\end{array}$ & Cost \\
\hline \multirow{7}{*}{ State } & $\mathrm{CO}_{2}$ Emission & Ton & Cost \\
\hline & $\mathrm{CO}_{2}$ Emission Per Unit of GDP & Ton/10 000 Yuan & Cost \\
\hline & Per Capita CO2 Emission & Ton/ 10000 persons & Cost \\
\hline & Consumption of Chemical Fertilizers, Pesticides & 10000 tons & Cost \\
\hline & Composition of Petroleum & $\%$ & Cost \\
\hline & Composition of Coal & $\%$ & Cost \\
\hline & Composition of Natural Gas & $\%$ & Benefit \\
\hline \multirow{6}{*}{ Impact } & Contributions of the Tertiary Industry & $\%$ & Benefit \\
\hline & Days Meeting Grade & Day & Benefit \\
\hline & Unemployment Rate & $\%$ & Cost \\
\hline & Deviation of Annual Precipitation & $\mathrm{mm}$ & Cost \\
\hline & Deviation of the Average Annual Temperature & ${ }^{\circ} \mathrm{C}$ & Cost \\
\hline & Area of Farm Crops Covered by Natural Disasters & 1000 hectares & Cost \\
\hline \multirow{6}{*}{ Response } & Efficiency of Energy Conversion & $\%$ & Benefit \\
\hline & Forest Coverage Rate & $\%$ & Benefit \\
\hline & Green Area in Built-up Areas & Hectare & Benefit \\
\hline & Attainment Rate of Sewage Discharge & $\%$ & Benefit \\
\hline & $\begin{array}{l}\text { Comprehensive Utilization Rate of Industrial Solid } \\
\text { Waste }\end{array}$ & $\%$ & Benefit \\
\hline & Environmental Finance Expenditure & 100 million Yuan & Benefit \\
\hline
\end{tabular}




\section{Evaluation of low-carbon economic development level}

\section{Data Sources}

The data that calculated the low-carbon economic development in this paper were from the statistical yearbook and the report on the State of the Environment in hebei province from 2007 to 2013. A few indexes were calculated based on the statistical data.

From the current literature, $\mathrm{CO}_{2}$ Emission calculated by the formula of $\mathrm{CO}_{2}=\mathrm{KE}$. Here $\mathrm{E}$ represented the different types of energy consumption; K represented the carbon emission intensity. In the research, because of the different carbon emission coefficients, the total carbon emissions were different from different scholars and institutions. In this paper, the coefficient of carbon emissions of coal, petroleum, natural gas was $0.7266,0.5588$ and 0.4241 respectively referenced the relevant research [14]. Then it calculated the total carbon emissions in Hebei Province during 2007-2013, and calculated the carbon emissions per unit of GDP and carbon emissions per capita. The results showed in Table 2.

Table 2. The annual emissions of $\mathrm{CO}_{2}$ and related indexes in hebei Province

\begin{tabular}{|l|c|c|c|c|c|c|c|}
\hline & 2007 & 2008 & 2009 & 2010 & 2011 & 2012 & 2013 \\
\hline $\mathrm{CO}_{2}$ emission & 1.411096 & 1.549618 & 1.680113 & 1.731649 & 1.809845 & 1.939568 & 2.067837 \\
\hline $\begin{array}{l}\mathrm{CO} \\
\mathrm{GDP}\end{array}$ & 1.409389 & 1.351301 & 1.234713 & 1.081472 & 1.050069 & 0.951036 & 0.843473 \\
\hline Per Capita $\mathrm{CO}_{2}$ emission & 2.059693 & 2.246474 & 2.419866 & 2.477678 & 2.572995 & 2.696241 & 2.855927 \\
\hline
\end{tabular}

\section{Calculation and Analysis}

There are four basic steps of the TOPSIS method. (a) First, we establish the initial decision matrix: $n_{i j}=x_{i j} / \sqrt{\sum_{i=1}^{m} x_{i j}^{2}}(i=1,2, \mathrm{~L}, m ; j=1,2, \mathrm{~L}, n)$; (b) Based on the normalized initial matrix, we find the optimal scheme and the worst scheme (i.e., positive and negative ideal solution): $\quad A^{+}=\left\{v_{1}^{+}, v_{2}^{+}, \mathrm{L}, v_{n}^{+}\right\}=\left\{\left(\max v_{i j} \mid j \in I\right),\left(\min v_{i j} \mid j \in I\right)\right\} \quad A^{-}=\left\{v_{1}^{-}, v_{2}^{-}, \mathrm{L}, v_{n}^{-}\right\}=\left\{\left(\min v_{i j} \mid j \in I\right),\left(\max v_{i j} \mid j \in I\right)\right\} \quad$, $v_{i j}=\omega_{j} \cdot n_{i j} \circ$ (c) We calculate the distance between the optimal solution and the worst solution: $d_{i}^{+}=\sqrt{\sum_{j=1}^{n}\left(v_{i j}-v_{j}^{+}\right)^{2}}, d_{i}^{-}=\sqrt{\sum_{j=1}^{n}\left(v_{i j}-v_{j}^{-}\right)^{2}}$, and get the relative closeness: $:_{r_{i}^{*}=\frac{d_{i}^{-}}{d_{i}^{+}+d_{i}^{-}}}(i=1,2, \mathrm{~L}, m) .(\mathrm{d})$, At last, we sort it and take the value as the basis for the evaluation.

According to the procedure of the entropy method and the TOPSIS, we first converted the original data by using the method of positive and dimensionless, and got the standard matrix F.

$F=\left|\begin{array}{cccccccccc}0.253842 & 0.295082 & 0.295701 & 0 & 0 & \mathrm{~L} & 0 & 0.147353 & 0 & 0 \\ 0.223212 & 0.237705 & 0.255327 & 0.033723 & 0.034526 & \mathrm{~L} & 0.041101 & 0.041488 & 0.168230 & 0.034523 \\ 0.193886 & 0.106557 & 0.199626 & 0.0833 & 0.085384 & \mathrm{~L} & 0.080003 & 0 & 0.168387 & 0.045535 \\ 0.163908 & 0.106557 & 0.138692 & 0.139015 & 0.142114 & \mathrm{~L} & 0.144986 & 0.117531 & 0.204659 & 0.154231 \\ 0.134582 & 0.127049 & 0.069533 & 0.167364 & 0.169335 & \mathrm{~L} & 0.193342 & 0.220168 & 0.312226 & 0.242326 \\ 0.030571 & 0 & 0.041121 & 0.240552 & 0.239086 & \mathrm{~L} & 0.261921 & 0.231686 & 0.082552 & 0.277008 \\ 0 & 0.127049 & 0 & 0.336046 & 0.329556 & \mathrm{~L} & 0.278647 & 0.241774 & 0.063946 & 0.246377\end{array}\right|$

Then we used the entropy weight method to determine the weight of each index. According to the concept of entropy, the greater the index value difference was, the greater weights of evaluation indexes were. We got the index entropy $\mathrm{w}_{\mathrm{j}}$ by using the formula of entropy weight method.

$$
w_{j}=\left(\begin{array}{llllllllll}
0.026583 & 0.02372 & 0.03173 & 0.033399 & 0.032596 & \mathrm{~L} & 0.030089 & 0.025869 & 0.026983 & 0.034825
\end{array}\right)
$$

Next, it used the vector standardization method to calculate the standardization decision matrix. So, we got the weighted and standardized matrix $\mathrm{X}$ by multiplying the each evaluation index weight and the corresponding normalized matrix. 


$X=\left|\begin{array}{cccccccccc}0.009802 & 0.008445 & 0.010795 & 0.007501 & 0.007566 & \mathrm{~L} & 0.009069 & 0.009787 & 0.008616 & 0.00453 \\ 0.009869 & 0.008639 & 0.011105 & 0.008592 & 0.008611 & \mathrm{~L} & 0.009702 & 0.009493 & 0.010419 & 0.006319 \\ 0.009934 & 0.009083 & 0.011531 & 0.010195 & 0.010149 & \mathrm{~L} & 0.010301 & 0.009379 & 0.010421 & 0.00689 \\ 0.009999 & 0.009083 & 0.011998 & 0.011996 & 0.011864 & \mathrm{~L} & 0.011301 & 0.009704 & 0.010809 & 0.012523 \\ 0.010064 & 0.009014 & 0.012528 & 0.012913 & 0.012688 & \mathrm{~L} & 0.012045 & 0.009989 & 0.011962 & 0.017089 \\ 0.010292 & 0.009444 & 0.012746 & 0.01528 & 0.014797 & \mathrm{~L} & 0.0131 & 0.01002 & 0.009501 & 0.018887 \\ 0.010359 & 0.009014 & 0.013061 & 0.018367 & 0.017533 & \mathrm{~L} & 0.013358 & 0.010048 & 0.009302 & 0.017299\end{array}\right|$

Finally, it evaluated the Euclidean distance between the object and the positive, negative ideal solution, which was $\mathrm{di}^{+}$and $\mathrm{di}^{-}$respectively. We got the low-carbon economy comprehensive evaluation value $\mathrm{ci}^{*}$ by using the formula $\mathrm{Ci}^{*}=\mathrm{di}^{-} /\left(\mathrm{di}^{+}+\mathrm{di}^{-}\right)$. See Table 3.

Table 3. Comprehensive evaluation value of low-carbon economy in Hebei Province

\begin{tabular}{|c|c|c|c|c|c|c|c|}
\hline Year & 2007 & 2008 & 2009 & 2010 & 2011 & 2012 & 2013 \\
\hline di- & 0.01864 & 0.01405 & 0.01729 & 0.02159 & 0.02802 & 0.03203 & 0.03478 \\
\hline di+ & 0.03318 & 0.03473 & 0.03101 & 0.02161 & 0.01895 & 0.01462 & 0.01631 \\
\hline ci $^{*}$ & 0.35967 & 0.28808 & 0.35797 & 0.49982 & 0.59657 & 0.68658 & 0.68083 \\
\hline
\end{tabular}

\section{Conclusions}

It can sort the seven years' situations of the low-carbon economy in Hebei Province according to the comprehensive evaluation value $\mathrm{ci}^{*}$. The $\mathrm{ci}^{*}$ are greater, the level of low-carbon economy is higher; on the contrary, the ci* values are smaller, the level of low-carbon economic development are lower. Therefore, as shown in Table 3, we can see that the development level of low-carbon economy in Hebei province from 2007 to 2013, it shows the following characteristics.

First of all, from the trend, it has shown a good development trend of the low-carbon economy in Hebei province, which the ci* increase from 0.35967 in 2007 to 0.68083 in 2013. it is a obvious rising trend, and it also shows that Hebei province has made great efforts to develop the low-carbon economy. The low-carbon economic development has achieved a good result during this period.

Secondly, although the trend is on the rise, it appears obvious fluctuation in the middle year. The development level of the ranking is 2012, 2013, 2011, 2010, 2007, 2009, 2008. From 2007 to 2013, it shows a similar trend of $U$ type. The lowest value of $\mathrm{ci}^{*}$ appeared in 2008 , which is 0.28808 . The maximum value of $\mathrm{ci}^{*}$ appeared in 2012, which is 0.68658 . The comprehensive evaluation values of 2008 and 2009 were lower than in 2007. It began to show an increasing trend from 2008, and then declined in 2013. It shows that the development level of low-carbon economy in Hebei province is not smooth.

Low-carbon economy is in line with the future development, but the development of low-carbon economy is not accomplished soon. The consumption of energy is different in different industries, and the carbon intensity is different. The process of the low-carbon economic development is constantly adjusting and optimizing. Because of the huge resource consumption in Hebei Province, it is necessary to optimize and adjust the industrial structure. The lagging effect of industrial adjustment on the development of low-carbon economy exists, and it also considers the local development and the traditional industrial structure. It is normal for the temporary volatility in the development of low-carbon economy, but the general trend is toward positive direction.

\section{Acknowledgment}

This paper is supported by the National Natural Science Foundation of China (No. 71373022) and by the Soft Science Project of Hebei Province (15454202D). 


\section{References}

[1] Xi Jingping, Communiqué of the Third Plenary Session of the 18th Central Committee of the Communist Party of China, November 12, 2013.

[2] Ma Jun, Zhou Lin, Li Wei, Indicator System Construction for Urban Low-carbon Economy Developmen, Science \& Technology Progress and Policy, Vol.27,2010, pp165-167.

[3] Xiao Cuixian, Tang Shanmao, Study on Assessment Index System of Low-Carbon Economy of City, Ecolgical Economy, Vol.234,2011, pp45-48.

[4] Feng Bi-mei, Study on the Construction of Low-carbon Economy Evaluation in Hubei Province, China Population, Resources and Environement, Vol.21, 2011,pp.54-58.

[5] Hu Dali ,Ding Shuai, Research on Evaluation Index System of Low-carbon Economy, Science \& Technology Progress and Policy, Vol. 38, 2010, pp.160-164.

[6]LI Gang, WANG Zhong-dong, ZHANG Ming, Research on the Low-Carbon Economy Evaluation Model Based on Circulating Revision , Journal of Northeastern University(Natural Science), Vol. 32, 2011, pp.1790-1794.

[7] Sun Wensheng, Yang Hongyan, Low-carbon Economy Evaluation Index System and Comprehensive Evaluation--a Case Study of Hebei Province, Journal of Hebei University of Economics and Business, Vol.33,2012, pp.54-58.

[8] Jia Lijiang Lu Guangdi, Assessment of Regional Low-carbon Economic Development Based on the Output of Non-consensual DEA. Journal of Industrial Technological Economics, Vol. 27,2012, pp.94-99.

[9] Chen Xirui,Zhang Rongzhen, Application of TOPSIS method in dynamic evaluation of regional ecological security, Journal of Northwest A\&F University(Nat. Sci. Ed.)Vol.39, 2011, pp.177-154.

[10] EEA. Environmental Indicators: Typology and Overview. Technical report no.25. EEA. Coppenhagen,1999.

[11] Joana H. Martins, Ana S. Camanho, Miguel B. Gaspar. A review of the application of driving forces-Pressure-State-Impact-Response framework to fisheries management, Ocean \& Coastal Management, Vol.69,2012, pp. 273-281.

[12] Simon Bell, DPSIR: A Problem Structuring Method: An exploration from the "Imagine" approach, European Journal of Operational Research.,Vol.222, 2012,pp.350-360.

[13] H.Meyar-Naimin,S.Vaez-Zadeh, Sustainable development based energy policy making frameworks, a critical review,Energy Policy,Vol.43,2012, pp.351-361.

[14] Wu Hong, Gu Shuzhong, Zhou Hong, etc. Relationships between Energy Comsumption-Carbon Emissions and Economic Growth in Hebei Province, Resources Science,Vol.33, 2011,pp.1897-1905. 